\title{
Autologous platelet-rich plasma therapy - a promising method for tissue repair/ /regeneration in many medical fields
}

\author{
Łukasz Piszczorowicz ${ }^{(}$, Dorota Król@, Stanisław Dyląg \\ Preparation Department, Regional Blood Donation and Blood Treatment Centre in Katowice, Poland
}

\begin{abstract}
Platelet-rich plasma (PRP) is commonly used in many medicinal fields and the interest in its application for management of numerous pathologies is recently growing. Platelets (PLT) contain physiologically active proteins called growth factors (GFs) that accelerate tissue regeneration. This process of tissue regeneration is stimulated through application of PRP prepared from autologous blood according to special protocol. The purpose of the protocol is to achieve high concentration of platelets within a small volume of plasma. PRP is a biological product with a platelet concentration above the baseline for the patient's peripheral blood. The PRP therapy is based on autologous procedures therefore the risk of infection is remote although some clinical conditions preclude the use of PRP as it may induce adverse reactions. The procedure of PRP preparation is relatively inexpensive and can be performed quickly in the patient's presence.

In the literature of the subject there are wide variations in PRP definitions with reference to protocols of preparation, platelet concentration and activation as well as in the manner of application to injured tissue and finally in the assessment of therapy outcome. It is therefore difficult to compare and confirm the efficacy of PRP therapy used for the management of various diseases. Authors clearly emphasize the urgent need for standardizing protocols of PRP preparation and application in various disorders. Although in general PRP therapy is considered a promising method for treatment of tissue injuries, the lack of standardized preparation procedures and ways of PRP application raises numerous questions and controversies.

The aim was to present review of literature related to the use of PRP and the mechanism of action of this blood derivative.
\end{abstract}

Key words: platelet-rich plasma (PRP), PRP preparation, platelets (PLT), growth factors (GFs), tissue regeneration

J. Transf. Med. 2020; 13: 135-148

Correspondence address: Łukasz Piszczorowicz, MSc, Preparation Department, Regional Blood Donation and Blood Treatment Centre in Katowice, 15 Raciborska St, 40-074 Katowice, Poland, Tel. +48 505082 450, E-mail: lpiszczala@wp.pl Translation: mgr Krystyna Dudziak 


\section{Introduction}

The term platelet-rich plasma (PRP) was first created by hematologists in the ' 70 s to describe plasma with a platelet count higher than that of peripheral blood. It was initially used for treatment of thrombocytopenia. Ten years later, PRP was applied in maxillofacial surgery and then in sports medicine [1]. In 1974, Kohler and Lipton found platelets to be the source of fibroblast growth-promoting activity [2]. In the subsequent years, platelets were demonstrated as the source of many growth factors (GFs). The most important growth factors are: platelet derived growth factor (PDGF), transforming growth factor $\beta 1$ (TGF- $\beta 1$ ), transforming growth factor $\beta 2$ (TGF$\beta 2$ ), insulin-like growth factor (IGF), epidermal growth factor (EGF), vascular endothelial growth factor (VEGF), fibroblast growth factor (FGF) and hepatocyte growth factor (HGF) [3-5]. In 1987, the first clinical application of autologous PRP was reported by Ferrari et al. in Italy. They described the procedure of PRP application during open heart surgeries. Administration of autologous platelet concentrates and red blood cells required no intraoperative autologous blood transfusions and therefore the cost of procedure was low [6]. Since then the interest in these components has markedly increased and their application was extended onto other medicinal fields. In 1994, Tayapongsak et al. first used PRP in mandibular reconstruction [7], and since 1997, PRP has been applied in oral and maxillofacial surgery $[8,9]$. Simultaneously, there appeared reports on advancement in the use of fibrin glue. Fibrinogen concentrates containing factor XIII and sometimes aprotinin as antifibrinolytics were applied for renewal of damaged peripheral nerves first on animal models (1972) then in humans (1974). Commercially available fibrin glues have been widely used in Europe since the 1970s. In the United States however, the first fibrin glue had not been approved by the Food and Drug Administration (FDA) until 1998 due to concerns about possible viral transmission [10]. In 1997, Whitman et al. were the first to describe the method of preparing platelet rich plasma. As result of activating substances (eg. thrombin) added to platelet rich plasma, platelet gel is obtained which is an alternative to fibrin glue [8]. The first and second decades of the 21 st century brought about increased interest in the application of PRP for management of sport injuries, especially tendinopathy [11-14], also in dermatology, mainly for scar revision, skin rejuvenation and alopecia [1].

\section{Various types of platelet products used in regenerative medicine}

In literature, many terms are alternately used in reference to platelets applied in regenerative medicine. This only brings about confusion in medical terminology. While describing surgical procedures, authors most often refer to the term PRP in the sense of platelet-rich plasma. PRP is a product in which platelet activation has not yet occurred. In order to obtain a clinical effect, platelets must be stimulated either by external activators (e.g. bovine thrombin, calcium chloride) or in a natural way - with no external stimulation - through stimulation of collagen in the injured tissue. With platelet activation, the clotting process is initiated and release of growth factors from platelet granules occurs. The product has a gel-like consistency and is called platelet-rich gel (PRG). With regard to preparation method and mechanism/pathway of platelet activation, we distinguish platelet rich plasma (PRP) and platelet rich fibrin (PRF). Application of $P R P$ requires activating substances, while for PRF application no external activators are required and the clotting process occurs naturally. The method of platelet activation has impact on fibrin structure and the rate of growth factor release (gradual or rapid). The clinical mechanisms of action for PRP and PRF are therefore slightly different. Scientific literature comes forward with many suggestions regarding the classification of these products. According to one, the products are classified into 4 categories with regard to leukocyte concentration and fibrin structure: pure platelet rich plasma (P-PRP), leukocyte- and plateletrich plasma with high leukocyte count (L-PRP), pure platelet-rich fibrin (P-PRF), leukocyte- and platelet-rich fibrin (L-PRF) [15]. In some literature reports another terminology is used such as: autologous platelet-rich plasma (aPRP) [16], plasma rich in growth factors (PRGFs) [17], platelet-rich concentrate (PRC) [18], advanced platelet rich fibrin (A-PRF) and injectable platelet-rich fibrin (i-PRF) [19].

There is no one definition of PRP. In scientific literature however the product is most often referred to as plasma with platelet concentration several fold higher than that in peripheral blood (baseline). In 2001, Marx reported 1 million platelets in $1 \mu$ l of the product (i.e. platelet concentration 4-5 fold higher than in whole blood) [20]. Jungbluth et al. suggested to apply PRP at platelet concentration 3-5 fold higher than baseline [21]. Cho et al. proposed platelet concentration 3-7-fold higher 
[22], while Franchini et al. applied PRP at platelet concentration even 14-fold higher than baseline [23]. On the other hand, Anitua et al. achieved good clinical effects with platelet concentration of 300 thousand/ $\mu 1$ [24].

In 2006, Graziani et al. studied the effect of various PRP concentrations on the in vitro proliferation on human osteoblasts and fibroblasts. The maximum effect was achieved with platelet concentration $2.5 \mathrm{x}$ higher than baseline, while PRP with still higher platelet concentration was found to reduce cell proliferation [25].

In 2004, Weibrich et al. compared the effect of PRP at three different platelet concentrations on bone regeneration in rabbits. After 3 and 4 weeks of applying PRP with platelet concentrations 2-6 fold higher than baseline, a $90 \%$ increase of bone mass was reported as compared to the control group. No stimulation effect was observed at platelet concentrations lower than $2 \times$ baseline, while at platelet concentrations $6-11$ fold higher than baseline, bone formation was inhibited [26].

Depending on the preparation protocol, the PRP content may significantly differ in terms of platelet and leukocyte count and growth factor content [27]. In 2014, Ehrenfest et al. suggested a system of PRP classification with regard to leukocyte count into: leukocyte-rich platelet-rich plasma(LRPRP) and leukocyte-poor platelet -rich plasma (LP-PRP). LR-PRP is obtained from buffy coat with higher centrifugation speeds or double centrifugation of whole blood, while LP-PRP is obtained at lower speeds and with single centrifugation [28]. Some authors point out that leukocytes are a source of pro-inflammatory cytokines, which may negatively affect tissue healing. Others indicate that LR-PRP accelerates healing of infected soft tissues. Apart from their immunological functions, leukocytes release additional quantities of growth factors and manifest anti-nociceptive properties due to released anti-inflammatory cytokines (IL-4, IL-10 and IL-13) and opioid peptides ( $\beta$-endorphin, met-enkephalin and dynorphin-A) [29].

\section{Application}

PRP is a therapeutic option for different pathologies in such medicinal fields as: surgery, orthopedics, dermatology (cosmetic medicine included), dentistry, urology, ophthalmology, otolaryngology, sports medicine, as well as veterinary medicine. PRP is used in general surgery, maxillofacial surgery, major vascular surgery, obstetrics and gynecological surgery (i.e. hysterectomy, ce- sarean section), cardiothoracic surgery, cosmetic and facial plastic surgery and neurosurgery. It is applied in procedures such as: bone reconstruction (e.g. jaw reconstruction) or tooth extraction. In sports medicine, PRP is used for management of tendons (tendinopathy), muscles, ligaments and meniscical tears; in dermatology it is used for treatment of chronic ulcers and burn wounds. It is also used in skin grafting [7, 9, 11, 24, 30-37].

Aesthetic medicine offers micro-needling procedures (mesotherapy) which consist in performing numerous fine needle punctures of the skin with special devices such as Derma Pen ${ }^{\circledR}$ or Derma Roller ${ }^{\circledR}$. Micro-wounds are then formed in which platelets and neutrophils release additional amounts of growth factors inducing inflammatory processes. As result, new collagen fibres are formed. Mesotherapy is also paired with plateletrich plasma for treatment of acne scars, baldness as well as the so-called "vampire facelift". Growth factors stimulate fibroblast activity to boost collagen and elastin production. Wrinkles are smoothed out and the symptoms of erythema or edema are reduced [38, 39].

\section{Platelet rich plasma as source of growth factors that stimulate tissue repair}

Wound healing is a complex process usually initiated in the blood clot, hence the interest in blood as source of platelets and platelet-released substances that accelerate healing [40]. It is common belief that for tissue regeneration to occur it is recommended to apply biomaterial containing the so-called Lynch triad. The components of the Lynch triad are: 1 ) a synthetic or natural tissue matrix; 2) mediators affecting target cells of the injured tissue (growth factors, cell adhesion factors [adhesins], hormones, vitamins); 3) cells mediated by mediators: undifferentiated stem cells, partially differentiated cells (preosteoblasts, fibroblasts, chondroblasts) or differentiated cells (fibrocytes, osteocytes). PRP meets two requirements of the Lynch triad - it is both the matrix and contains mediator-releasing platelets; it has no cell mediated cells [41].

Following activation, platelets change shape and develop cytoplasmic projections (pseudopodia) which enable movement within the clot matrix for more effective regeneration of the injured tissue. Like other cells, platelets have various intracellular structures such as $\alpha$ granules which release growth factors crucial for tissue repair and hemostasis. Growth factors are signaling cells (ligands) which 
affect specific receptors and act like hormones through autocrine, paracrine or endocrine signaling. Growth factors regulate expression of other growth factors and are controlled by a feedback mechanism [4, 30, 40, 42, 43]. Table 1 presents the classification of growth factors and their biological functions.

Other growth factors to be found in PRP are: brain-derived neurotrophic factor (BDNF), $\beta$-nerve growth factor $(\beta$-NGF), ciliary neurotrophic factor (CNTF) belonging to the IL-6 family, connective tissue growth factor (CTGF), granulocyte colonystimulating factor (G-CSF), macrophage colonystimulating factor (M-CSF), granulocyte-macrophage colony-stimulating factor (GM-CSF) and growth differentiation factors (GDFs), a TGF- $\beta$ subfamily [49].

Intensive growth factor release begins in platelets within the first 10 minutes of initiation of the clotting process; the vast majority of growth factors $(>95 \%)$ is released within the first hour of platelet activation. Over the next several days, platelets synthesize and release additional amounts of growth factors [18, 31].

PRP is not only the source of growth factors but also of adhesins, i.e. osteo-conductive proteins responsible for epithelial cell migration [50].

The mechanism of action of PRP is well illustrated on a model of jaw reconstruction developed by Marx et al. in the late 1990s following transplant of substantia spongiosa (spongy bone). In 2007, in their review article Wrotniak, Bielecki and Gaździk presented the following description of the process. They observed that the difference in oxygenation between the site of bone defect and the healthy tissue is crucial for bone repair. At defect-site, oxidation is $5-9$ fold lower as compared to normal and $\mathrm{pH}$ is $4-6$. These conditions are chemotactic for wound-cleaning macrophages that are an additional source of growth factors. Following PRP application the process of bone reconstruction begins when PDGF, TGF- $\beta 1$ and IGF are released from platelet granules. PDGF stimulates mitogenesis of osteogenic cell and bone marrow stem cell. As result, the number of cells markedly increases. PDGF also stimulates angiogenesis through division of endothelial cells and budding of new capillary branches within the graft. TGF- $\beta$ initially stimulates fibroblasts and pre-osteoblasts to cell division (mitosis), which results in the increase in number and differentiation into mature osteoblasts. TGF- $\beta$ stimulates osteoblasts to bone matrix formation and fibroblasts to collagen synthesis. Capillary ingrowth is thus supported. IGF affects osteoblasts and stimulates bone trabeculae formation within the transplanted spongy bone. Approximately on day 3 , the appearance of graft-penetrating capillaries is observed and complete graft vascularization occurs on day $14-17$. The initially high cellular activity is mostly due to PDGF, TGF- $\beta$ and IGF and in a lesser degree to other growth factors. Platelet survival time in injured tissue as well as the growth factor effect lasts approximately 5 days. The process of bone repair may then continue either through increase in the number of stem cells and their differentiation into osteoblasts (which then release TGF- $\beta$ and IGF into the bone matrix) or through a more dominant mechanism based on chemotaxis and activation of macrophages. After 3 days, the effect of platelet PDGF weakens and macrophages take over the function of releasing growth factors. The newly formed bone is an immature woven structure devoid of Haversian canals and structural integrity. This is bone formation-phase I which occurs during the first 4 weeks after transplant. Approximately 4 weeks later, the oxygen gradient disappears and the immature bone undergoes gradual resorption and transformation into mature form with a micro fibrous lamellar structure. This is the so called bone - phase II with Haversian canals, intraosseous and periosteum. Responsible for this process are IGF and BMPs which bind to the bone matrix and are released by osteoclasts during the process of bone remodeling [35].

It is believed that the evolutionary goal of growth factor- induced regenerative processes is to save energy and to use it effectively. From this perspective, it would be most ineffective to maintain a large population of repair cells with no other function to perform. The number of repair cells decreases with age. If necessary, the growth factor-based system can rapidly increase the pool of such repair cells and to stimulate their activity during the healing process [35].

The amount of released growth factors is correlated not only with the number of activated platelets but also with the method of blood collection, centrifugation spin, speed, time and temperature, the overall preparation time, type of anticoagulant and platelet activators added to PRP. The choice of preparation protocol is of key importance as it may affect premature platelet activation and growth factor release [31].

\section{Advantages of autologous platelet rich plasma}

The main advantage of autologous PRP is safety. PRP from autologous blood is safer than allogenic agents burdened with higher risk of im- 
Table 1. Growth factors in platelet rich plasma - classification and functions [3-5, 18, 32, 41, 44-48]

\begin{tabular}{|c|c|}
\hline Growth factor & Classification and functions \\
\hline \multirow{9}{*}{$\begin{array}{l}\text { Platelet derived } \\
\text { growth factor } \\
\text { (PDGF) }\end{array}$} & - 5 homo- or heterodimeric forms: PDGF-AA, PDGF-BB, PDGF-AB, PDGF-CC, PDGF-DD \\
\hline & $\begin{array}{l}\text { - Acts through } \alpha \text {-receptors of target cell membrane and affects their gene expression. Damage to } \\
\text { PDGF } \alpha \text {-receptor results in disorders of craniofacial and skeletal embryogenesis }\end{array}$ \\
\hline & $\begin{array}{l}\text { - Released by platelets, fibroblasts and keratinocytes. In the later regeneration phase, also produced } \\
\text { by smooth-muscle cells, activated macrophages or vascular endothelial cells }\end{array}$ \\
\hline & $\begin{array}{l}\text { - Mitogenic and chemotactic for mesenchymal cells: fibroblasts, smooth-muscle cells, glial cells, } \\
\text { neutrophils and macrophages }\end{array}$ \\
\hline & - Angiogenesis stimulator \\
\hline & - Stimulates epithelial formation \\
\hline & - Stimulates osteocyte and chondrocyte proliferation \\
\hline & - Accelerates effect of other GFs on target cells, e.g. macrophages \\
\hline & - Controls bone resorption and remodeling through increased number of osteoclasts \\
\hline \multirow{5}{*}{$\begin{array}{l}\text { Transforming } \\
\text { growth factors- } \beta \\
\text { (TGFs- } \beta \text { ) }\end{array}$} & $\begin{array}{l}\text { - This growth factor family includes: TGF- } \beta 1 \text {, TGF- } \beta 2 \text { and TGF- } \beta 3 \text {, bone morphogenetic proteins } \\
\text { (BMPs) and activins }\end{array}$ \\
\hline & - Mitogenic for fibroblasts, osteoblasts, smooth muscle cells; regulates their metabolism \\
\hline & $\begin{array}{l}\text { - Stimulates extracellular matrix formation and angiogenesis through vascular endothelial cell } \\
\text { activation }\end{array}$ \\
\hline & - Stimulates osteoclast apoptosis; bone formation has advantage over bone resorption \\
\hline & - Major role in wound healing \\
\hline \multirow{6}{*}{$\begin{array}{l}\text { Vascular endo- } \\
\text { thelial growth } \\
\text { factors (VEGFs) }\end{array}$} & $\begin{array}{l}\text { - The growth factor family includes: VEGF-A, VEGF-B, VEGF-C, VEGF-D, VEGF-E and placental growth } \\
\text { factor (PIGF) }\end{array}$ \\
\hline & - Stimulates angiogenesis, enhances mitogenesis and vascular permeability (mostly endothelium) \\
\hline & - Anti-apoptotic properties: induces IAP proteins (inhibitors of apoptosis) \\
\hline & - One of major GFs during embryogenesis and vascular endothelial cell proliferation \\
\hline & $\begin{array}{l}\text { - Responsible for reorganization of the extracellular matrix through inducing expression } \\
\text { of plasminogen activators and their inhibitors as well as metalloproteinases }\end{array}$ \\
\hline & $\begin{array}{l}\text { - Participates in neurogenesis and neuroprotection of the central and peripheral nervous system; } \\
\text { stimulates growth of Schwann cells, proliferation and migration of astrocytes as well as } \\
\text { endothelium to produce neurotrophic substances }\end{array}$ \\
\hline \multirow[t]{5}{*}{$\begin{array}{l}\text { Epidermal gro- } \\
\text { wth factors } \\
\text { (EGFs) }\end{array}$} & $\begin{array}{l}\text { - The family of growth factors includes: epidermal growth factor (EGF), heparin binding EGF } \\
\text { (HB-EGF), transforming growth factor } \alpha \text { (TGF- } \alpha \text { ), epiregulin, amphiregulin, betacellulin, epigene, } \\
\text { neuregulin-1 (NRG-1), NRG-2, NRG-3, NRG-4, NRG-5 and NRG-6 }\end{array}$ \\
\hline & - Released by platelets, macrophages and fibroblasts \\
\hline & - Mitogenic for fibroblasts, keratinocytes and endothelial cells \\
\hline & - Stimulates epithelial cell differentiation, keratinocyte migration and epithelial angiogenesis \\
\hline & - Boost collagen activity; chemotactic for endothelial cells \\
\hline \multirow{4}{*}{$\begin{array}{l}\text { Fibroblast gro- } \\
\text { wth factors } \\
\text { (FGFs) }\end{array}$} & - FGF-2, FGF-7 and FGF-10 - crucial for wound healing \\
\hline & $\begin{array}{l}\text { - FGF-2, also referred to as basic fibroblast growth factor (bFGF), affects granulation and tissue re- } \\
\text { modeling. Regulates synthesis and deposition of various extracellular matrix components, boosts } \\
\text { keratinocyte mobility and stimulates fibroblast migration and collagen production }\end{array}$ \\
\hline & - FGF-7, also called keratinocyte growth factor-1 (KGF-1), crucial for tissue neo-vascularization \\
\hline & $\begin{array}{l}\text { - FGF-7 (together with FGF-10) mitogenic for keratinocytes, stimulate their differentiation and } \\
\text { migration which is crucial for tissue re-epithelialization. Protect keratinocytes against apoptosis, } \\
\text { increase transcription of factors that remove reactive oxygen species }\end{array}$ \\
\hline \multirow{4}{*}{$\begin{array}{l}\text { Insulin-like gro- } \\
\text { wth factor-1 } \\
\text { (IGF-1) }\end{array}$} & - Modulator of apoptosis \\
\hline & $\begin{array}{l}\text { - Together with PDGF, promote bone regeneration through osteoblast proliferation } \\
\text { and differentiation }\end{array}$ \\
\hline & - Chemotactic for fibroblasts \\
\hline & - Affect keratinocyte migration \\
\hline
\end{tabular}


Table 1 cont. Growth factors in platelet rich plasma - classification and functions [3-5, 18, 32, 41, 44-48]

\begin{tabular}{|c|c|}
\hline Growth factor & Classification and functions \\
\hline \multirow{8}{*}{$\begin{array}{l}\text { Hepatocyte gro- } \\
\text { wth factor (HGF) }\end{array}$} & - Stimulate angiogenesis \\
\hline & - Mitogenic for hepatocytes and endothelial cells \\
\hline & - Key factor for tissue self-repair in animal models \\
\hline & $\begin{array}{l}\text { Protect liver, kidneys, lungs, heart, brain and gastrointestinal mucosa, due to anti-apoptotic } \\
\text { and anti-inflammatory properties (as demonstrated on animal models) }\end{array}$ \\
\hline & HGF neutralization at embryonic stage leads to hypoplasia \\
\hline & - Cytotoxic effect on some cancer cells \\
\hline & $\begin{array}{l}\text { - One of glucose controlling factors - preventive against hyperglycaemia, stimulates insulin } \\
\text { secretion }\end{array}$ \\
\hline & - Increases hair growth \\
\hline \multirow{3}{*}{$\begin{array}{l}\text { Platelet factor-4 } \\
\text { (PF-4) }\end{array}$} & - Anti-heparin effect, stimulates clot formation \\
\hline & - Chemotactic for fibroblasts \\
\hline & - Stimulates initial neutrophil influx into injured tissue \\
\hline $\begin{array}{l}\text { Human platelet- } \\
\text {-derived endo- } \\
\text { thelial growth } \\
\text { factor (PDEGF) }\end{array}$ & - Accelerates wound healing, stimulates proliferation of keratinocytes and cutaneous fibroblasts \\
\hline $\begin{array}{l}\text { Platelet-derived } \\
\text { angiogenesis } \\
\text { factor (PDAF) }\end{array}$ & - Stimulates angiogenesis \\
\hline
\end{tabular}

munogenic reactions or microbial transmission from other donors [18, 40, 51].

Another advantage are antimicrobial $[52,53]$ and antifungal [54] properties. Dense granules of activated platelets release not only growth factors but also a number of biologically active substances such as proaccelerin, serotonin, catecholamines and antimicrobial proteins. Thrombin-activated human platelets release 7 proteins which belong to the group of antimicrobial peptides (HPAPs):

- fibrinopeptide A (FP-A);

- fibrinopeptide B (FP-B);

- thymosin $\beta-4$ (T $\beta-4)$;

- platelet basic protein (PBP);

- connective tissue activating peptide 3 (CTAP-3);

- RANTES protein;

- platelet factor 4 (PF-4) $[24,54]$.

In their microbiological in vitro studies performed in 2002, Tanga et al. confirmed the antimicrobial and antifungal efficacy of these proteins against: Escherichia coli, Staphylococcus aureus, Candida albicans and Cryptococcus neoformans. The higher the peptide concentration, the larger the bacteria and fungi inhibition zone. The optimal antimicrobial and antifungal efficacy of each protein of the HPAPs group is observed at slightly different $\mathrm{pH}$; antifungal activity is greater at acidic $\mathrm{pH}$, while the optimum of antimicrobial activity is observed at slightly alkaline $\mathrm{pH}$ [54].
An interesting, though not yet fully investigated phenomenon is the relation between sensitivity of some bacterial strains and the type of plateletactivating thrombin (bovine or human) [55].

Application of autologous PRP has also been observed to have an analgesic potential which contributes to reduction of the amount of prescribed pain killers as well as blood loss after surgical procedures [34, 56, 57]. In their studies on analgesic properties of PRP, Fanning et al. assessed pain perception of 55 women after major gynecologic surgery. In the study group the women were given PRP and experienced less, short-lasting pain and therefore the amount of prescribed analgesics could be reduced [34]. In 2009, Johal et al. performed a meta-analysis of 78 randomized placebocontrolled trials (RCTs) which comprised 5308 patients subjected to orthopedic surgery with PRP. Up to date this is the largest RCT review in this topic field. A statistically significant reduction in pain perception was recorded for humeral epicondylitis and knee osteoarthritis, while for muscle injuries, rotator cuff repair or reconstruction of anterior cruciate ligament, the analgesic effect was negligible or statistically insignificant. As matter of interest, neither the leukocyte or platelet count nor the platelet activators had effect on the results. The authors also analyzed 3 attempts at management of humeral epicondylitis where 
application of whole blood or the so-called dry needling procedures brought about a similar effect as PRP application. The authors offer two explanations. The use of whole blood or mere stimulation of inflammatory processes and local bleeding in injured tissue may have induced release of sufficient amounts of therapeutic agents to achieve an analgesic effect (though not comparable to that following PRP application). The other explanation is that a placebo effect may have occurred. The authors emphasize the need for further research in order to determine the differences between the two treatment protocols [58].

Equally important advantages of PRP are the relatively easy preparation procedure and short preparation time (about 30 minutes from blood collection to application) as well as low cost [59].

\section{Risk associated with application of platelet rich plasma}

Although the advantages of PRP therapy are undisputable, there are also risk factors that need to be considered one of which is microbial infection. PRP is prepared from blood collected by venipuncture and stored at room temperature; such conditions may promote bacterial proliferation [60]. It should be noted that in treatment protocols based on PRP injections, skin is punctured and there is the risk of infection and mechanical tissue injury. However, if appropriate procedures are followed and the medical personnel maintains sterility regime, the risk is minimized [30,61].

PRP initiates the coagulation process, therefore - if applied inadequately — it may trigger an intravascular coagulation process.

In some cases, application of PRP may induce adverse reactions, as it stimulates the body's defense mechanism. In the past, bovine thrombin added to PRP for platelet activation was found responsible for eliciting immune responses in some patients. Bovine thrombin administered together with bovine factor Va was responsible for life-threatening coagulopathies due to development of antibodies against human coagulation factors such as thrombin, factor XI and in particular factor V. Since 1997, factor Va has been eliminated from the manufacturing process of bovine thrombin $[8,18,62,63]$.

In the course of growth factor-rich therapies it is crucial to avoid skin exposure to sun light because it is not entirely clear what effect UV radiation may have on the expression and function of TGF- $\beta$. UV radiation interferes with the transduction of the TGF- $\beta$-mediated signal to the cell nucleus, which may have carcinogenic effect on developing skin cancer [64].

Application of PRP is not recommended for patients with blood coagulation disorders and co-existing thrombocytopenia or hypofibrinogenemia [18], for nursing or pregnant women, cancer patients or patients with infectious diseases. Moreover, application of local anaesthetics (such as lidocaine or bupivacaine (Marcaine) prior to PRP injections may put patients at additional risk, particularly those who are allergic to these drugs. Prior to procedure patients should therefore be informed of the possible adverse reactions [61].

Another controversial issue is the leukocyte content in PRP. Leukocytes release catabolic enzymes, such as matrix metalloproteinases, which may delay the healing process [65]. In addition, neutrophils may contribute to tissue injury by releasing reactive oxygen species [66].

\section{Limitations vs effectiveness of applying platelet rich plasma}

A vast majority of studies on the application of PRP were conducted on small groups of patients. Few of such studies were randomized, hence their low value as compared to the outcome of evidencebased medicine (EBM). In their randomized clinical trials (in small groups of patients) of bone implants, Gołos and Treliński (2014) report no benefit of PRP for the healing process as compared to control. Raghoebar et al. (2005) also demonstrated no statistical differences between control and patients subjected to autologous bone transplant during surgery of the maxillary sinus wall following PRP application. Results of randomized studies on the treatment of anterior cruciate ligament injuries showed no advantage of platelet rich plasma treatment [30]. In 2018, in the literature review of the topic, Sumanovac reported differences in the clinical efficacy of PRP in various orthopedic procedures. According to the author, most literature reports suggest that the effect of PRP in knee osteoarthritis lasts for up to 12 months. Current studies on the effectiveness of PRP are inconclusive but some have demonstrated greater therapeutic efficacy of PRP as compared to placebo or hyaluronic acid. Some concern about the quality of publications as well as high risk of work-bias should however be considered as well as difficulties in assessment of clinical efficacy of PRP. Difficulties in comparing results of different studies are an additional challenge due to the lack of standardization of PRP preparation protocols [67]. 
On the other hand, the clinical efficacy of PRP has been demonstrated in 2010 by Alissa et al. in a dental study which confirmed accelerated wound healing following tooth extraction, also in 2012 by Simonpieri et al. who reported good therapeutic outcome of bone-defect management as well as by Patela et al. for knee osteoarthritis in a randomized study of 150 patients [30, 36]. In 2017, Miron et al. in their review of the impact of PRF on soft tissue healing, reported that in 27 out of 31 (87\%) clinical trials, the application of PRF brought about a statistically significant improvement in various medical procedures, including dental procedures [68]. In 2018, Chen et. al in their systematic review of 8 randomized and 16 cohort studies (24) on PRP in androgenic alopecia therapy, reported 21 studies with positive clinical results $(88 \%)$ and 3 with no clinical improvement following surgery [69]. The beneficial effects of PRP application have also been demonstrated after bone implants and surgical treatment of periodontal defects, in plastic surgery in the treatment of chronic wounds (including diabetic foot), in facial reconstructive surgery or after gynecologic procedures. Several randomized clinical trials on chronic tendinopathy management reported a beneficial though delayed effect of PRP. A meta-analysis of research on PRP application is therefore a challenge due to variety of anatomical structures under study, demographic differences (professional athletes, amateurs), differences in PRP preparation protocols, in injection technique, post-surgical rehabilitation, and evaluation of therapy outcome [30].

The PRP therapy is now more advanced and more frequently relied on in various medicinal fields for treatment of both people and animals. Since 2015, PRP has been used for endometrial growth promotion (thin endometrium disorders) [70], and in the recent years attempts have been made at PRP management of carpal tunnel syndrome [71], empty nose syndrome [72], Sjögren's syndrome [73] or management of dry eye syndrome through application of platelet rich plasma in form of eye drops [74]. In 2019, studies were performed on Alzheimer's mice which were applied plasma rich in growth factors. The study aim was to assess the impact of growth factors on disruption of blood-brain barrier integrity and functions and the effect on amyloid $\beta$ deposition. Although the results of initial in vitro studies were promising, in vivo studies demonstrated increased disease-related pathology [17].

More recent attempts are directed at application of platelet-rich plasma in the management of erectile dysfunction [75] and cosmetic gynecology, e.g. for vaginal rejuvenation [76] or the so-called "O-shot" [77] treatments aimed at restoring pleasure in sex life by revitalization of female intimate areas.

\section{Preparation, application and classification of platelet rich plasma}

PRP is obtained by differential centrifugation of whole blood collected into special tubes or commercially available sterile kits from different manufacturers. Blood draw occurs with the addition of an anticoagulant, e.g. ACD-A (Anticoagulant Citrate Dextrose Solution, Solution A) and it is then centrifuged at different speeds depending on the manufacturer's instructions. Red blood cell fraction is separated from platelet rich plasma (PRP) and platelet-poor plasma (PPP) fractions [40]. It should be noted that the centrifugation procedure may cause lysis and fragmentation of some platelets which results in premature release of bioactive growth factors. Choice of optimal centrifugation parameters is therefore of crucial importance [18]. PRP preparation through centrifugation is such a simple procedure that it can be performed in the physician's office or the operating room. Centrifugation must take place under sterile conditions and the parameters should be adjusted so as to separate platelet mass from red blood cells without causing platelet lysis. Following centrifugation, the platelet layer is extracted together with a small volume of plasma [50].

Depending on the system, the volume of blood collected from the patient varies from 9 to $120 \mathrm{ml}$ [30]. Blood is collected into special containers or syringes with anticoagulant which contains sodium citrate at a volume ratio of $10: 1$. The most commonly used anticoagulant is ACD solution (Acid Citrate Dextrose) which is optimal for maintaining platelet viability [48]. The properties of CPD solution (Citrate Phosphate Dextrose) are similar but $10 \%$ less effective for maintaining platelet viability [20]. On the other hand, EDTA solution (ethylenediaminetetraacetic acid) is a potentially harmful anticoagulant which may cause platelet injury [48]. Blood is subjected to one or two centrifugations. After initial centrifugation, blood is separated into three fractions: RBC, PRP and PPP. The layer of $\mathrm{PRP}$ is syringe-removed from above other layers and subjected to second centrifugation to obtain higher platelet yield. The final volume of the product ranges from 3 to $32 \mathrm{ml}$ and also depends on the system used [30].

Immediately before PRP application to the target site, platelet activators are added (usually 
bovine thrombin, less often recombinant as well as $10 \%$ solution of $\mathrm{CaCl}_{2}$ at a volume ratio of $6: 1$ or 10: 1) in order to stimulate platelet degranulation and to initiate the clotting process. When PRP is applied by way of injection, apart from standard syringes also special two-cannula syringe are in use. The applicator structure allows the components to mix immediately before application to the target tissue [18, 48, 78-80]. Ultrasound, X-ray or MRI imaging are used during PRP application as well as in follow-up examinations [40, 81].

Platelet activation may also occur without the help of additives. Platelet-rich fibrin (PRF) is a new generation platelet concentrate predominantly used in dentistry, oral and maxillofacial surgery. Application of PRF is simpler as it requires no substances such as anticoagulants or activators. Clot formation occurs naturally and has a more flexible fibrin network, as compared to activated PRP. Within this network cells can migrate and growth factor release is prolonged [78]. In 2018, $\mathrm{Du}$ et al. described an innovative, temperaturedependent method of PRP preparation and activation which they called temperature controlled PRP (t-PRP). They obtained t-PRP as result of double centrifugation of whole blood at $4^{\circ} \mathrm{C}$ and activation was induced by heating the product to $37^{\circ} \mathrm{C}$. Platelet-rich plasma obtained with this technique was found to have better physiological characteristics as compared to conventional PRP activated with additional substances. The process of growth factor release occurred more slowly and was prolonged [82]. Harrison et al. demonstrated the effect of the method of platelet activation on the dynamics of growth factor release. During platelet activation with thrombin or calcium chloride, growth factors are released immediately, while during natural activation (contact of target tissue with collagen) the process occurs gradually and is extended over a longer period of time [83]. An interesting method of platelet activation still under investigation is photo activation with polychromatic (near infrared band) light at a wavelength of $600-1200 \mathrm{~nm}$ [84]. Another alternative method is pulse electric field stimulation licensed in 2019 by Neculaes et al. Modifications of these methods allow to achieve the effect of prolonged and controlled process of growth factor secretion. Optimization of these methods leads to higher concentrations of growth factors at no clot formation which would make PRP application difficult. This is an advantage over conventional methods which rely on activating substances [85].

There are various commercial systems for PRP production available on the market (Table 2) [86]. They differ with regard to volume of collected blood (9-120 ml), number of centrifugations (1-2), spin speed and temperature as well as platelet yield [30].

Worldwide there is a variety of commercially available methods used for preparation of PRP. In their 2019 review of 876 papers, Fadadu et al. identified as many as 33 systems and protocols for PRP production which differed with regard to preparation conditions and platelet yield in the final product. The authors emphasized the need

Table 2. Characteristics of commercial systems used for PRP preparation [86]

\begin{tabular}{|c|c|c|c|c|c|c|c|}
\hline System & $\begin{array}{l}\text { Blood } \\
\text { volume } \\
\text { [ml] }\end{array}$ & Centrifugation & $\begin{array}{l}\text { Time } \\
{[\min .]}\end{array}$ & $\begin{array}{l}\text { Final PRP } \\
\text { volume } \\
\text { [ml] }\end{array}$ & $\begin{array}{c}\text { Multiple of } \\
\text { baseline PLT } \\
\text { concentration }\end{array}$ & Leukocytes & Activator \\
\hline $\begin{array}{l}\text { ACP-DS (Arthrex, } \\
\text { Naples, FL) }\end{array}$ & 9 & Single/one & 5 & 3 & $\times 2-3$ & Absent & Absent \\
\hline \multirow{2}{*}{$\begin{array}{l}\text { Fibrinet (Cascade; } \\
\text { Musculoskeletal Tis- } \\
\text { sue Foundation) }\end{array}$} & \multirow[t]{2}{*}{$9-18$} & Single for PRP & 6 for PRP & \multirow[t]{2}{*}{$4-9$} & \multirow[t]{2}{*}{$\times 1-1.5$} & \multirow[t]{2}{*}{ Absent } & \multirow[t]{2}{*}{$\mathrm{CaCl}_{2}$} \\
\hline & & Double for PRFM & $\begin{array}{l}15 \text { for } \\
\text { PRFM }\end{array}$ & & & & \\
\hline GPS (Biomet) & $27-110$ & Single & 15 & $3-12$ & $\times 3-8$ & Present & $\mathrm{TA} / \mathrm{CaCl}_{2}$ \\
\hline $\begin{array}{l}\text { Magellan (Medtro- } \\
\text { nic, Minneapolis, } \\
\text { MN) }\end{array}$ & $30-60$ & Single & $4-6$ & 6 & $\times 3-7$ & Present & $\mathrm{CaCl}_{2}$ \\
\hline $\begin{array}{l}\text { PRGF (BTI Biotech- } \\
\text { nology Institute) }\end{array}$ & $9-72$ & Single & 8 & $4-32$ & $\times 2-3$ & Absent & $\mathrm{CaCl}_{2}$ \\
\hline $\begin{array}{l}\text { SmartPrep (Harvest } \\
\text { Technologies, } \\
\text { Plymouth, MA) }\end{array}$ & $20-120$ & Single & 14 & $3-20$ & $\times 4-6$ & Present & $\mathrm{TB} / \mathrm{CaCl}_{2}$ \\
\hline
\end{tabular}

$\mathrm{CaCl}_{2}$ - calcium chloride; PRFM - platelet-rich fibrin matrix; TA - autologous thrombin; TB - bovine thrombin 
for standardization of PRP separation protocols for better understanding of treatment methods based on platelet-rich plasma [87]. In their review of scientific literature covering 105 studies performed in the years 2006-2016, Chahla et al. found that only 11 papers (10\%) presented a detailed description of reproducible preparation protocols and only $17(16 \%)$ included a quantitative measurement of the chemical composition of final PRP product [88]. In response to the call for standardization of PRP preparation and application protocols, in 2012 DeLong et al. came forward with the PAW classification system based on: 1) absolute number of platelets, 2) mechanism of platelet activation and 3) the presence or absence of white cells. With regard to platelet concentration the authors classify PRP into: P1 (concentration lower or equal baseline platelet value in peripheral blood), $\mathrm{P} 2$ (higher than baseline $-750,000 \mathrm{PLT} / \mu \mathrm{l}), \mathrm{P} 3$ ( $>750,000-$ $1,250,000 \mathrm{PLT} / \mu \mathrm{l})$ and P4 (> 1,250,000 PLT/ $\mu \mathrm{l})$ [89]. In the same year, Mishra et al. developed a classification system which distinguished 4 types of PRP: I. LR-PRP; II. LR-PRP gel; III. LP-PRP; IV. LP-PRP gel. The system took into account leukocyte presence (types I and II) or absence (types III and IV) and use of platelet activators (types II and IV) or no activators (types I and III). This system also included the criterion of platelet concentration: lower (type A) or higher (type B) than 5 fold baseline platelet value in peripheral blood [81]. In 2015, Mautner et al. developed a more accurate classification system based on: PRP concentration (PLT/ $\mu \mathrm{l})$, presence or absence of leukocytes (\% of neutrophils) and RBCs, and the presence or absence of activators. They named the system PLRA for Platelets, Leukocytes, Red blood cells and Activation [90]. In 2016, Magalon et al. developed a similar classification system - DEPA based on factors such as: 1) dose of injectable platelets, 2) efficiency of production expressed as percentage of platelet recovery, 3) purity of PRP - percentage of platelets against RBC and white blood cell count, 4) mechanism of PRP activation - factor or mixture of factors used for platelet activation. These classification systems are helpful for comparing different protocols of PRP preparation [91]. Lana et al. (2017) emphasized the special role of peripheral blood mononuclear cells (PBMCs) that may be present in PRP. The pool of PBMCs includes monocytes and lymphocytes involved not only in the immune response, but also in the process of regeneration through cytokine release. Cytokines perform various functions: chemotactic, pro and anti-inflammatory, proliferation-promoting or modulating the release functions of other cells. In view of the above, the authors point to the need of quantification of PBMCs in PRP and propose still another classification system- MARSPILL. The system also includes the parameters of PRP preparation and application such as: 1) method of obtaining PRP - automated (M, machine) or manual (H, handmade); 2) number of spins ( $\mathrm{Sp} 1$ or $\mathrm{Sp2}$ ); 3) presence of red blood cells (RBC-R, RBC$\mathrm{P})$; 4) platelet concentration (multiple of baseline platelet yield): PL: 2-3, PL: 4-6, PL: $6-8$ and PL: 8-10); 5) presence of leukocytes (Lc-R, Lc-P) and leukocyte count; 6$)$ platelet activation $(\mathrm{A}+, \mathrm{A}-)$; 7) photo activation $(\mathrm{L}+, \mathrm{L}-)$ and imaging guidance during PRP application (G+, G-). The authors define low-erythrocyte $\mathrm{PRP}$ as a product with $\mathrm{RBC}$ content 15x lower as compared to the patient's peripheral blood, while LR-PRP and LP-PRP are defined as having a higher or lower leukocyte count respectively, as compared to baseline. Moreover, the MARSPILL classification system requires the use of a hematology analyzer for more accurate differentiation and quantification of cells in PRP. The MARSPILL acronym is derived from: method $(\mathrm{M})$, activation (A), red blood cells $(\mathrm{R})$, spin (S), platelets $(\mathrm{P})$, image guidance (I), leukocytes (L), light/photo activation (L). The authors found it justified to include photo-activation of PRP as one of the parameters of the newly created classification system in view of the new, promising reports regarding positive effects of light-activated PRP in the management of knee osteoarthritis [92].

\section{Summary}

Up to date publications allow to consider PRP therapy as relatively safe for the reason that the product is autologous $[18,40,51]$. The preparation procedure is simple, inexpensive and quick, often to be performed at the patient's bed side [59]. PRP has antimicrobial, antifungal properties [52-54] as well as analgesic impact, which allows to economize on the use of narcotic analgesics [34, 58].

Despite numerous studies and promising treatment effects, there is still the need for largescale randomized studies to confirm the therapeutic properties of PRP [26].

Great hope is also associated with combined therapy, where the effect of PRP is supported by mesenchymal stem cells (MSC) and gene therapy [79, 93].

In the literature review on PRP preparation protocols by Dohan Ehrenfest, Rasmusson and Albrektsson (2009) the world market of platelet concentrates is perceived as a "jungle" of commercial 
offers and products of doubtful standardization [94]. The large number of currently available protocols of PRP preparation and application is a challenge to the scientific environment in the sense that efforts should be made to develop international guidelines for standardization of PRP preparation and clinical application with regard to specific pathologies and disorders. Most authors acknowledge that platelet-rich plasma is a promising method of tissue repair but at the same time they emphasize the importance of standardization [30,42].

\section{Conflict of interests}

The authors declare no conflict of interest. PRP products are prepared at the Regional Blood Transfusion Center in Katowice and distributed to medical centers to be used for commercial medical procedures. No person or organization has contributed financially to this publication or has exerted influence on the content.

\section{References}

1. Alves R, Grimalt R. A review of platelet-rich plasma: history, biology, mechanism of action, and classification. Skin Appendage Disord. 2018; 4(1): 18-24, doi: 10.1159/000477353, indexed in Pubmed: 29457008.

2. Kohler N, Lipton A. Platelets as a source of fibroblast growth-promoting activity. Exp Cell Res. 1974; 87(2): 297-301, doi: 10.1016/0014-4827(74)90484-4.

3. Eppley BL, Woodell JE, Higgins J. Platelet quantification and growth factor analysis from platelet-rich plasma: implications for wound healing. Plast Reconstr Surg. 2004; 114(6): 1502-1508, doi: 10.1097/01. prs.0000138251.07040.51, indexed in Pubmed: 15509939.

4. Barrientos S, Stojadinovic O, Golinko MS, et al. Growth factors and cytokines in wound healing. Wound Repair Regen. 2008; 16(5): 585-601, doi: 10.1111/j.1524-475X.2008.00410.x, indexed in Pubmed: 19128254.

5. Nakamura T, Mizuno S. The discovery of hepatocyte growth factor (HGF) and its significance for cell biology, life sciences and clinical medicine. Proc Jpn Acad Ser B Phys Biol Sci. 2010; 86(6): 588-610, doi: 10.2183/pjab.86.588, indexed in Pubmed: 20551596.

6. Ferrari M, Zia S, Valbonesi M, et al. A new technique for hemodilution, preparation of autologous platelet-rich plasma and intraoperative blood salvage in cardiac surgery. Int J Artif Organs. 2018; 10(1): 47-50, doi: 10.1177/039139888701000111.

7. Tayapongsak P, O'Brien D, Monteiro C, et al. Autologous fibrin adhesive in mandibular reconstruction with particulate cancellous bone and marrow. J Oral Maxillofac Surg. 1994; 52(2): 161-165, doi: 10.1016/0278-2391(94)90401-4.

8. Whitman DH, Berry RL, Green DM. Platelet gel: an autologous alternative to fibrin glue with applications in oral and maxillofacial surgery. J Oral Maxillofac Surg. 1997; 55(11): 1294-1299, doi: 10.1016/s0278-2391(97)90187-7, indexed in Pubmed: 9371122.

9. Taniguchi Yu, Yoshioka T, Sugaya H, et al. Growth factor levels in leukocyte-poor platelet-rich plasma and correlations with donor age, gender, and platelets in the Japanese population. J Exp Orthop. 2019; 6(1): 4, doi: 10.1186/s40634-019-0175-7, indexed in Pubmed: 30712144.

10. Evans LA, Morey AF. Current applications of fibrin sealant in urologic surgery. Int Braz J Urol. 2006; 32(2): 131-141, doi: 10.1590/ s1677-55382006000200002, indexed in Pubmed: 16650289.

11. de Vos RJ, Weir A, van Schie HTM, et al. Platelet-rich plasma injection for chronic Achilles tendinopathy: a randomized controlled trial. JAMA. 2010; 303(2): 144-149, doi: 10.1001/ jama.2009.1986, indexed in Pubmed: 20068208.

12. Sánchez M, Anitua E, Azofra J, et al. Comparison of surgically repaired Achilles tendon tears using platelet-rich fibrin matrices. Am J Sports Med. 2007; 35(2): 245-251, doi: 10.1177/0363546506294078, indexed in Pubmed: 17099241.

13. Mlynarek RA, Kuhn AW, Bedi A. Platelet-rich plasma (PRP) in orthopedic sports medicine. Am J Orthop 2016; 45(5): 290-326. PMID: 27552452.

14. Gholami M, Ravaghi H, Salehi M, et al. A systematic review and meta-analysis of the application of platelet rich plasma in sports medicine. Electron Physician. 2016; 8(5): 2325-2332, doi: 10.19082/2325, indexed in Pubmed: 27382440.

15. Dohan Ehrenfest DM, Bielecki T, Mishra A, et al. In search of a consensus terminology in the field of platelet concentrates for surgical use: platelet-rich plasma (PRP), platelet-rich fibrin (PRF), fibrin gel polymerization and leukocytes. Curr Pharm Biotechnol. 2012; 13(7): 1131-1137, doi: 10.2174/138920112800624328, indexed in Pubmed: 21740379.

16. Cohn CS, Lockhart E. Autologous platelet-rich plasma: evidence for clinical use. Curr Opin Hematol. 2015; 22(6): 527-532, doi: 10.1097/MOH.0000000000000183, indexed in Pubmed: 26390166.

17. Duong QV, Kintzing ML, Kintzing WE, et al. Plasma rich in growth factors (PRGF) disrupt the blood-brain barrier integrity and elevate amyloid pathology in the brains of 5XFAD mice. Int J Mol Sci. 2019; 20(6): 1489, doi: 10.3390/ijms20061489, indexed in Pubmed: 30934587.

18. Mehta S, Watson JT. Platelet rich concentrate: basic science and current clinical applications. J Orthop Trauma. 2008; 22(6): 432-438, doi: 10.1097/BOT.0b013e31817e793f, indexed in Pubmed: 18594311.

19. Kawase T, Tanaka T. An updated proposal for terminology and classification of platelet-rich fibrin. Regen Ther. 2017; 7: 80-81, doi: 10.1016/.j.reth.2017.10.002, indexed in Pubmed: 30271855.

20. Marx RE. Platelet-rich plasma (PRP): what is PRP and what is not PRP? Implant Dent. 2001; 10(4): 225-228, doi: 10.1097/00008505-200110000-00002, indexed in Pubmed: 11813662.

21. Jungbluth P, Wild M, Grassmann JP, et al. Platelet-rich plasma on calcium phosphate granules promotes metaphyseal bone healing in mini-pigs. J Orthop Res. 2010; 28(11): 1448-1455, doi: 10.1002/jor.21152, indexed in Pubmed: 20872580.

22. Cho JM, Lee YHo, Baek RM, et al. Effect of platelet-rich plasma on ultraviolet b-induced skin wrinkles in nude mice. J Plast Reconstr Aesthet Surg. 2011; 64(2): e31-e39, doi: 10.1016/j. bjps.2010.08.014, indexed in Pubmed: 20884308.

23. Franchini M, Dupplicato P, Ferro I, et al. Efficacy of Platelet Gel in Reconstructive Bone Surgery. Orthopedics. 2005; 28(2): 161-163, doi: 10.3928/0147-7447-20050201-19.

24. Anitua E, Andia I, Ardanza B, et al. Autologous platelets as a source of proteins for healing and tissue regeneration. Thromb Haemost. 2004; 91(1): 4-15, doi: 10.1160/TH03-07-0440, indexed in Pubmed: 14691563.

25. Graziani F, Ivanovski S, Cei S, et al. The in vitro effect of different PRP concentrations on osteoblasts and fibroblasts. Clin 
Journal of Transfusion Medicine 2020, tom 13, nr 2

Oral Implants Res. 2006; 17(2): 212-219, doi: 10.1111/j.1600-0501.2005.01203.x, indexed in Pubmed: 16584418.

26. Weibrich G, Hansen T, Kleis W, et al. Effect of platelet concentration in platelet-rich plasma on peri-implant bone regeneration. Bone. 2004; 34(4): 665-671, doi: 10.1016/j.bone.2003.12.010, indexed in Pubmed: 15050897.

27. Oudelaar BW, Peerbooms JC, Huis In ,t Veld R, et al. Concentrations of blood components in commercial platelet-rich plasma separation systems: a review of the literature. Am J Sports Med. 2019; 47(2): 479-487, doi: 10.1177/0363546517746112, indexed in Pubmed: 29337592.

28. Castillo TN, Pouliot MA, Kim HJ, et al. Comparison of growth factor and platelet concentration from commercial platelet-rich plasma separation systems. Am J Sports Med. 2011; 39(2): 266-271, doi: 10.1177/0363546510387517, indexed in Pubmed: 21051428.

29. Ehrenfest DMD, Andia I, Zumstein MA, et al. Classification of platelet concentrates (platelet-rich plasma-PRP, platelet-rich fibrin-PRF) for topical and infiltrative use in orthopedic and sports medicine: current consensus, clinical implications and perspectives. Muscles Ligaments Tendons J. 2019; 04(01): 03, doi: 10.32098/mltj.01.2014.02.

30. Gołos A, Treliński J. Kliniczne zastosowanie osocza bogatopłytkowego. Hematologia 2014; 5(3): 252-259; https:/journals.viamedica.pl/hematologia/article/view/40225/34375.

31. Jameson C. Autologous Platelet Concentrate for the Production of Platelet Gel. Laboratory Medicine. 2007; 38(1): 39-42, doi: 10.1309/3ua5hwyvknce01ar.

32. Floryan KM, Berghoff WJ. Intraoperative use of autologous platelet-rich and platelet-poor plasma for orthopedic surgery patients. AORN J. 2004; 80(4): 668-674, doi: 10.1016/s00012092(06)61320-3, indexed in Pubmed: 15526700.

33. Moradi O, Seyyed MG, Mohammad MD, Sedaghat R, Akbarein H. Effects of platelet rich plasma (PRP) and platelet rich growth factor $\left(\mathrm{PRGF}{ }^{\circledR}\right)$ on the wound healing of distal part of limbs in horses. IJVS 2013; 8(1): 41-47. [http://www.ivsajournals.com/art icle_3633_1e5d5a813e0dc3a01a2502483a99fe89.pdf].

34. Fanning J, Murrain L, Flora R, et al. Phase I/II prospective trial of autologous platelet tissue graft in gynecologic surgery. J Minim Invasive Gynecol. 2007; 14(5): 633-637, doi: 10.1016/j. jmig.2007.05.014, indexed in Pubmed: 17848327.

35. Wrotniak M, Bielecki T, Gaździk TS. Current opinion about using the platelet-rich gel in orthopaedics and trauma surgery. Ortop Traumatol Rehabil. 2007; 3(6): 227-238.

36. Alissa R, Esposito M, Horner K, et al. The influence of platelet-rich plasma on the healing of extraction sockets: an explorative randomised clinical trial. Eur J Oral Implantol. 2010; 3(2): 121-34. PMID: 20623037.

37. Moraes VY, Lenza M, Tamaoki MJ, et al. Platelet-rich therapies for musculoskeletal soft tissue injuries. Cochrane Database Syst Rev. 2013(12): CD010071, doi: 10.1002/14651858.CD010071. pub2, indexed in Pubmed: 24363098.

38. Elghblawi E. Medical micro-needling. Trichol Cosmetol Open J. 2017; 1(1): 21-24. doi: 10.17140/TCOJ-1-105.

39. Sand JP, Nabili V, Kochhar A, et al. Platelet-rich plasma for the aesthetic surgeon. Facial Plast Surg. 2017; 33(4): 437-443, doi: 10.1055/s-0037-1604240, indexed in Pubmed: 28753720.

40. Chomicki-Bindas P, Zakrzewski P, Pomianowski S. Platelet concentrates, as new and promising agent in the orthopedic surgery - an introduction. Borgis - Post Nauk Med 2010; 23(2): 153-157.

41. Bielecki T, Gaździk TS, Cieślik-Bielecka A, Cieślik T. Application of the platelet rich plasma as biomaterial stimulating tissue re- generation and reparation processes. Inż Biomater 2004; 7(34): $22-25$.

42. Roffi A, Filardo G, Assirelli E, et al. Does platelet-rich plasma freeze-thawing influence growth factor release and their effects on chondrocytes and synoviocytes? Biomed Res Int. 2014; 2014: 692913, doi: 10.1155/2014/692913, indexed in Pubmed: 25136613.

43. Lubkowska A, Dołęgowska B, Banfi G. Growth factor content in PRP and their applicability in medicine. J Biol Regul Homeost Agents 2012; 26(2): 3-22. PMID: 23648195.

44. ten Dijke P, Hansen P, Iwata KK, et al. Identification of another member of the transforming growth factor type beta gene family. Proc Natl Acad Sci U S A. 1988; 85(13): 4715-4719, doi: 10.1073/ pnas.85.13.4715, indexed in Pubmed: 3164476.

45. Houde N, Chamoux E, Bisson M, et al. Transforming growth factor-beta1 (TGF-beta1) induces human osteoclast apoptosis by up-regulating Bim. J Biol Chem. 2009; 284(35): 23397-23404, doi: 10.1074/jbc.M109.019372, indexed in Pubmed: 19574221.

46. Tran J, Rak J, Sheehan C, et al. Marked induction of the IAP family antiapoptotic proteins survivin and XIAP by VEGF in vascular endothelial cells. Biochem Biophys Res Commun. 1999; 264(3): 781-788, doi: 10.1006/bbrc.1999.1589, indexed in Pubmed: 10544009.

47. Bielawska L, Kopczyński P, Szubińska P, Baszczuk A, Kopczyński Z. Evaluation of release rate of vascular endothelial growth factor (VEGF) by activated in vitro platelets in platelet-rich plasma. Post Nauk Med. 2014; 27(12B): 5-10.

48. Alsousou J, Thompson M, Hulley P, et al. The biology of platelet-rich plasma and its application in trauma and orthopaedic surgery: a review of the literature. J Bone Joint Surg Br. 2009; 91(8): 987-996, doi: 10.1302/0301-620X.91B8.22546, indexed in Pubmed: 19651823.

49. Krüger JP, Freymannx U, Vetterlein S, et al. Bioactive factors in platelet-rich plasma obtained by apheresis. Transfus Med Hemother. 2013; 40(6): 432-440, doi: 10.1159/000356329, indexed in Pubmed: 24474894.

50. Marx RE. Platelet-rich plasma: evidence to support its use. J Oral Maxillofac Surg. 2004; 62(4): 489-496, doi: 10.1016/j. joms.2003.12.003, indexed in Pubmed: 15085519.

51. Wang C, Xu M, Guo W, et al. Clinical efficacy and safety of platelet-rich plasma in arthroscopic full-thickness rotator cuff repair: A meta-analysis. PLoS One. 2019; 14(7): e0220392, doi: 10.1371/journal.pone.0220392, indexed in Pubmed: 31356630 .

52. Kour P, Pudakalkatti PS, Vas AM, et al. Comparative evaluation of antimicrobial efficacy of platelet-rich plasma, platelet-rich fibrin, and injectable platelet-rich fibrin on the standard strains of Porphyromonas gingivalis and Aggregatibacter actinomycetemcomitans. Contemp Clin Dent. 2018; 9(Suppl 2): S325-S330, doi: 10.4103/ccd.ccd_367_18, indexed in Pubmed: 30294166.

53. Drago L, Bortolin M, Vassena C, et al. Plasma components and platelet activation are essential for the antimicrobial properties of autologous platelet-rich plasma: an in vitro study. PLoS One. 2014; 9(9): e107813, doi: 10.1371/journal.pone.0107813, indexed in Pubmed: 25232963.

54. Tang YQ, Yeaman MR, Selsted ME. Antimicrobial peptides from human platelets. Infect Immun. 2002; 70(12): 6524-6533, doi: 10.1128/iai.70.12.6524-6533.2002, indexed in Pubmed: 12438321.

55. Cieślik-Bielecka A, Bold T, Ziółkowski G, et al. Antibacterial Activity of Leukocyte- and Platelet-Rich Plasma: An Study. Biomed Res Int. 2018; 2018: 9471723, doi: 10.1155/2018/9471723, indexed in Pubmed: 30050949. 
56. Mochizuki T, Yano K, Ikari K, et al. Platelet-rich plasma for the reduction of blood loss after total knee arthroplasty: a clinical trial. Eur J Orthop Surg Traumatol. 2016; 26(8): 901-905, doi: 10.1007/s00590-016-1821-8, indexed in Pubmed: 27448283.

57. Tian WZ, Er JX, Liu L, et al. Effects of autologous platelet rich plasma on intraoperative transfusion and short-term outcomes in total arch replacement (sun's procedure): a prospective, randomized trial. J Cardiothorac Vasc Anesth. 2019; 33(8): 2163-2169, doi: 10.1053/j.jvca.2019.02.033, indexed in Pubmed: 31060939.

58. Johal H, Khan M, Yung SHP, et al. Impact of platelet-rich plasma use on pain in orthopaedic surgery: a systematic review and meta-analysis. Sports Health. 2019; 11(4): 355-366, doi: 10.1177/1941738119834972, indexed in Pubmed: 31136726.

59. Rutkowski J, Thomas J, Bering C, et al. An analysis of a rapid, simple, and inexpensive technique used to obtain platelet-rich plasma for use in clinical practice. J Oral Implantol. 2008; 34(1): 25-33, doi: 10.1563/1548-1336(2008)34[25:aaoars]2.0.co;2.

60. Buchholz DH, Young VM, Friedman NR, et al. Bacterial proliferation in platelet products stored at room temperature. Transfusion-induced Enterobacter sepsis. N Engl J Med. 1971; 285(8): 429-433, doi: 10.1056/NEJM197108192850803, indexed in Pubmed: 5283524.

61. Sampson S, Gerhardt M, Mandelbaum B. Platelet rich plasma injection grafts for musculoskeletal injuries: a review. Curr Rev Musculoskelet Med. 2008; 1(3-4): 165-174, doi: 10.1007/s12178008-9032-5, indexed in Pubmed: 19468902.

62. Everts PAM, Knape JTA, Weibrich G, et al. Platelet-rich plasma and platelet gel: a review. J Extra Corpor Technol. 2006; 38(2): 174-187, indexed in Pubmed: 16921694.

63. Zehnder JL, Leung LL. Development of antibodies to thrombin and factor $\mathrm{V}$ with recurrent bleeding in a patient exposed to topical bovine thrombin. Blood. 1990; 76(10): 2011-2016, doi: 10.1182/blood.v76.10.2011.bloodjournal76102011.

64. Ciążýska M, Bednarski I, Lesiak A. The role of TGF-b in photodegradation and carcinogenesis. Forum Dermatologicum 2016;2(2):60-3.

65. Sundman EA, Cole BJ, Fortier LA. Growth factor and catabolic cytokine concentrations are influenced by the cellular composition of platelet-rich plasma. Am J Sports Med. 2011; 39(10): 2135-2140, doi: 10.1177/0363546511417792, indexed in Pubmed: 21846925.

66. Tidball JG. Inflammatory cell response to acute muscle injury. Med Sci Sports Exerc. 1995; 27(7): 1022-1032, doi: 10.1249/00005768199507000-00011, indexed in Pubmed: 7564969.

67. Šmanovac A. Platelet-rich plasma in orthopaedics - to use or not to use? Orthopedics, Traumatology Spor Med Int J. 2018; 1(1): 5-6, doi: 10.30881/otsmij.00002.

68. Miron RJ, Fujioka-Kobayashi M, Bishara M, et al. Platelet-Rich Fibrin and Soft Tissue Wound Healing: A Systematic Review. Tissue Eng Part B Rev. 2017; 23(1): 83-99, doi: 10.1089/ten. TEB.2016.0233, indexed in Pubmed: 27672729.

69. Chen JX, Justicz N, Lee LN. Platelet-Rich Plasma for the Treatment of Androgenic Alopecia: A Systematic Review. Facial Plast Surg. 2018; 34(6): 631-640, doi: 10.1055/s-0038-1660845, indexed in Pubmed: 29954021.

70. Chang Y, Li J, Chen Y, et al. Autologous platelet-rich plasma promotes endometrial growth and improves pregnancy outcome during in vitro fertilization. Int J Clin Exp Med 2015; 8(1): 1286-1290. PMCID: PMC4358582.

71. Malahias MA, Chytas D, Mavrogenis AF, et al. Platelet-rich plasma injections for carpal tunnel syndrome: a systematic and compre- hensive review. Eur J Orthop Surg Traumatol. 2019; 29(1): 1-8, doi: 10.1007/s00590-018-2278-8, indexed in Pubmed: 30022241.

72. Di Mario A, Crescenzi D, Di Rienzo Businco L. Functional reconstruction of turbinates with growth factors and adipose tissue in the treatment of empty nose syndrome. J J Bone Stem Res 2015; 1(2): 1-9.

73. Jarka E. Review of Sjögren Syndrome: A Comparison of Two Topical Biologic Treatment Options. J Ophthalmol Clin Res. 2016; 3(3): 1-7, doi: 10.24966/ocr-8887/100024.

74. Avila MY, Igua AM, Mora AM. Randomised, prospective clinical trial of platelet-rich plasma injection in the management of severe dry eye. Br J Ophthalmol. 2018 [Epub ahead of print], doi: 10.1136/ bjophthalmol-2018-312072, indexed in Pubmed: 29970389.

75. Scott S, Roberts M, Chung E. Platelet-Rich Plasma and Treatment of Erectile Dysfunction: Critical Review of Literature and Global Trends in Platelet-Rich Plasma Clinics. Sex Med Rev. 2019; 7(2): 306-312, doi: 10.1016/j.sxmr.2018.12.006, indexed in Pubmed: 30833169.

76. Desai SA, Kroumpouzos G, Sadick N. Vaginal rejuvenation: From scalpel to wands. Int J Womens Dermatol. 2019; 5(2): 79-84, doi: 10.1016/j.ijwd.2019.02.003, indexed in Pubmed: 30997377.

77. Neto JB. O-Shot: Platelets Rich Plasma in Intimate Female Treatment. Journal of Women's Health Care. 2017; 06(05), doi: 10.4172/2167-0420.1000395.

78. Dohan DM, Choukroun J, Diss A, et al. Platelet-rich fibrin (PRF): a second-generation platelet concentrate. Part I: technological concepts and evolution. Oral Surg Oral Med Oral Pathol Oral Radiol Endod. 2006; 101(3): e37-e44, doi: 10.1016/j.tripleo.2005.07.008, indexed in Pubmed: 16504849.

79. Cieślik-Bielecka A, Bielecki T, Gaździk TS, Cieślik T. Growth factors in the platelet-rich plasma as autogenic material which stimulates bone healing processes. Czas Stomatol 2006; 59(7): 510-517.

80. Ogundipe OK, Ugboko VI, Owotade FJ, et al. Preparation of platelet-rich plasma from small volume of whole blood - a simplified approach. Niger Postgrad Med J 2012; 19(3): 133-136. PMID: 23064167.

81. Mishra A, Harmon K, Woodall J, et al. Sports medicine applications of platelet rich plasma. Curr Pharm Biotechnol. 2012; 13(7): 1185-1195, doi: 10.2174/138920112800624283, indexed in Pubmed: 21740373.

82. Du L, Miao Y, Li X, et al. A novel and convenient method for the preparation and activation of PRP without any additives: temperature controlled PRP. Biomed Res Int. 2018; 2018: 1761865, doi: 10.1155/2018/1761865, indexed in Pubmed: 29862255.

83. Harrison S, Vavken P, Kevy S, et al. Platelet activation by collagen provides sustained release of anabolic cytokines. Am J Sports Med. 2011; 39(4): 729-734, doi: 10.1177/0363546511401576, indexed in Pubmed: 21398575.

84. Irmak G, Demirtaş TT, Gümüşderelioğlu M. Sustained release of growth factors from photoactivated platelet rich plasma (PRP). Eur J Pharm Biopharm. 2020; 148: 67-76, doi: 10.1016/j. ejpb.2019.11.011, indexed in Pubmed: 31811895.

85. Neculaes VB, Torres AS, Caiafa A, Dun-Lan Lee B, Garner AL. Platelet activation and growth factor release using electric pulses. United States Patent No. US010369200B2. 2019.

86. Lopez-Vidriero E, Goulding KA, Simon DA, et al. The use of platelet-rich plasma in arthroscopy and sports medicine: optimizing the healing environment. Arthroscopy. 2010; 26(2): 269-278, doi: 10.1016/j.arthro.2009.11.015, indexed in Pubmed: 20141991.

87. Fadadu PP, Mazzola AJ, Hunter CW, et al. Review of concentration yields in commercially available platelet-rich plasma (PRP) 
systems: a call for PRP standardization. Reg Anesth Pain Med. 2019 [Epub ahead of print], doi: 10.1136/rapm-2018-100356, indexed in Pubmed: 30992411.

88. Chahla J, Cinque ME, Piuzzi NS, et al. A call for standardization in platelet-rich plasma preparation protocols and composition reporting: a systematic review of the clinical orthopaedic literature. J Bone Joint Surg Am. 2017; 99(20): 1769-1779, doi: 10.2106/ JBJS.16.01374, indexed in Pubmed: 29040132.

89. DeLong JM, Russell RP, Mazzocca AD. Platelet-rich plasma: the PAW classification system. Arthroscopy. 2012; 28(7): 998-1009, doi: 10.1016/j.arthro.2012.04.148, indexed in Pubmed: 22738751.

90. Mautner K, Malanga GA, Smith J, et al. A call for a standard classification system for future biologic research: the rationale for new PRP nomenclature. PM R. 2015; 7(4 Suppl): S53-S59, doi: 10.1016/j.pmrj.2015.02.005, indexed in Pubmed: 25864661.

91. Magalon J, Chateau AL, Bertrand B, et al. DEPA classification: a proposal for standardising PRP use and a retrospective appli- cation of available devices. BMJ Open Sport Exerc Med. 2016; 2(1): e000060, doi: 10.1136/bmjsem-2015-000060, indexed in Pubmed: 27900152.

92. Lana JF, Purita J, Paulus C, et al. Contributions for classification of platelet rich plasma - proposal of a new classification: MARSPILL. Regen Med. 2017; 12(5): 565-574, doi: 10.2217/rme-20170042, indexed in Pubmed: 28758836.

93. Amable PR, Carias RB, Teixeira MV, et al. Platelet-rich plasma preparation for regenerative medicine: optimization and quantification of cytokines and growth factors. Stem Cell Res Ther. 2013; 4(3): 67, doi: 10.1186/scrt218, indexed in Pubmed: 23759113.

94. Dohan Ehrenfest DM, Rasmusson L, Albrektsson T. Classification of platelet concentrates: from pure platelet-rich plasma (P-PRP) to leucocyte- and platelet-rich fibrin (L-PRF). Trends Biotechnol. 2009; 27(3): 158-167, doi: 10.1016/.j.tibtech.2008.11.009, indexed in Pubmed: 19187989. 